\title{
Muchas misiones y \\ varias lecturas
}

Pedro Cázares Aboytes

Universidad Autónoma de Sinaloa perryyorke55@hotmail.com

La obra Etnohistoria del ámbito posmisional en México, coordinada por Gilberto López Castillo, Cuauhtémoc Velasco Ávila y Modesto Aguilar Alvarado, se convertirá en una referencia de la historiografía regional tanto por su diversidad de ángulos como por los ámbitos analizados a partir de un eje temático que los aglutina: los procesos sociopolíticos y económicos desarro-
Reseña del libro Gilberto López Castillo, Cuauhtémoc Velasco Ávila y Modesto Aguilar Alvarado (coordinadores), Etnohistoria del ámbito posmisional en México, México, Instituto Nacional de Antropología e Historia, Consejo Nacional para la Cultura y las Artes

(Colección Historia-Serie Logos), 2013, 265 pp. llados principalmente en los territorios del norte, noroeste y occidente desde la época colonial hasta la revolución mexicana. Los actores sociales de este drama fueron misioneros de diversas órdenes, militares, indígenas y empleados de la corona española, quienes durante los tres siglos se vieron envueltos en un cúmulo de situaciones en las cuales no pocas veces se empataban sus intereses.

Respecto de la estructura del trabajo, es un texto compuesto por doce ensayos distribuidos en cuatro apartados. Éstos desarrollan temáticas de la geografía mexicana actual y pretérita de Texas, Nuevo México, Arizona, Nevada, la Alta California, Sonora, Baja California, Sinaloa, Chihuahua, Durango, Coahuila, Nuevo León, Tamaulipas, Jalisco y Michoacán. Lo anterior denota el interés por lograr una cobertura notable de la temática.

Una empresa de investigación como ésta necesariamente implicó la consulta de repositorios documentales de diversa índole: archivos municipales, estatales, nacionales y de al menos dos países más (Italia 
y Estados Unidos), colecciones privadas de corte eclesiástico, judicial, administrativo y militar principalmente, que suman un total de veintidós archivos registrados en las referencias de los trabajos en cuestión. Con base en lo anterior, se ve que no se escatimó en la materia prima con la cual se construiría este libro.

Entrando a los ensayos del texto, el primer apartado, "Etnohistoria y ámbito posmisional", está compuesto por dos escritos, el primero de José Refugio de la Torre Curiel y el segundo de Cuauhtémoc Velasco Ávila. De la Torre, en "La frontera misional novohispana a fines del siglo XVIII", realiza un balance y un análisis de la forma como se ha trabajado sobre las misiones. El autor, además de revisar y analizar de forma concienzuda el andamiaje teórico-metodológico con el cual se han acercado al estudio de las misiones novohispanas arqueólogos, antropólogos e historiadores, centró su ruta crítica de investigación en tres aspectos que considera básicos para entender la evolución del carácter y las funciones de las misiones novohispanas: la evolución económica, las respuestas indígenas a los proyectos religiosos y la recomposición demográfica. Sobre el final de su trabajo, concluyó que no existió un proyecto misional uniforme que constituyera un manual operativo o de funciones, sino que más bien cada contexto misional se fue configurando sobre la base de las diversas situaciones que le tocaba enfrentar, mediar o construir.

Cuauhtémoc Velasco Ávila, en "Etnogénesis y etnocidio. La suerte de los pueblos nómadas en las provincias internas de Oriente en el siglo XVIII", desde un análisis etnohistórico, inicialmente se concentra en revisar la manera en que han sido utilizados los conceptos de etnogénesis y etnocidio por la comunidad académica de donde emanaron y las posibilidades ofrecidas en el campo de las ciencias sociales para el estudio de espacios interculturales. El autor, a partir de las guías construidas por Cecilia Sheridan y José Luis Mirafuentes, encontró que a la par del ejercicio de una estrategia de control militar y violencia apabullante, la eliminación discursiva de toda aquella colectividad opuesta al posicionamiento del gobierno novohispano en aras de fincar núcleos poblacionales también sería borrada del papel. Aquí cabe decir que el discurso distaba mucho de ser letra muerta.

En la segunda parte, "Misiones, secularización y reformas: estudios de caso en épocas de transición", el lector encontrará tres trabajos. Abre el apartado Gilberto López Castillo con su texto "Rebeliones indígenas en el río Fuerte durante el siglo xviII. Problemas locales y solidaridades regionales". En el norte de Sinaloa, asiento de los indígenas mayos, denominados "fuerteños" en las fuentes de archivo, tuvieron lugar dos rebeliones armadas, una en 1740 y otra en 1769. ¿Cuáles fueron los motivos 
del alzamiento de quienes desde hacía décadas se encontraban en relativa tranquilidad? López Castillo localiza algunas de las acciones desplegadas por los rebeldes, su radio de acción, sus blancos, sus aliados y sus intentos de negociación. La violencia política fue ejercida tanto por los indígenas como por los españoles. Tales acciones deben ser enmarcadas dentro de un contexto de inflexión alimentado por el caldo de cultivo debido a las crecientes exigencias derivadas de la transición del régimen de los Habsburgo al de los Borbones.

En seguida, Juana Gabriela Román Jaquéz presenta su trabajo "Villa Unión: entrada a las misiones franciscanas de Río Grande", en el que brinda una panorámica de la forma en que tuvo lugar el proceso de poblamiento en la región de Río Grande en el actual estado de Coahuila hacia finales del siglo XVII por parte de la orden franciscana. La autora considera que existe un vacío historiográfico respecto del papel histórico de dicha región.

Al final del segundo apartado, Wilfrido Llanes y Gilberto López Castillo presentan su ensayo "Excomunión y antirregalismo en la subdelegación de Sinaloa a fines del dominio español" desde un estudio de caso en el cual exponen la conflictiva relación entre autoridades eclesiásticas y militares, donde cada una de las partes hizo su apropiación y uso particular de una serie de ordenanzas y normas que reforzaban la autoridad de la corona frente a un orden eclesiástico que lejos estaba de asumir una actitud pasiva o entreguista, sino que más bien se reformulaba a partir de su propia experiencia frente a tendencias dirigidas a aminorar su poder y someterlo gradualmente. El escenario es una exmisión, Mocorito, donde tuvieron lugar esas disputas jurisdiccionales, las cuales desembocaron en un conflicto con momentos de tensión que llegaron hasta el grado de la excomunión de un teniente.

En la tercera parte del libro, "Los nuevos escenarios: representaciones, instituciones, legislación y participación armada", está el trabajo de Érika Julieta Vázquez Flores, "La construcción del indígena en el imaginario de los intelectuales del siglo XIX". La autora revisa las posturas de Charles Hale, François-Xavier Guerra y David Brading, quienes a su vez analizan las ideas de Lorenzo de Zavala, José María Luis Mora y Lucas Alamán acerca de la idea de nación, las comunidades indígenas y la tenencia de la tierra.

Luego, Rosa Elba Rodríguez Tomp, en su texto "Las instituciones republicanas y los indios californios: ¿eternos menores de edad o ciudadanos?", estudia las actitudes de la Compañía de Jesús y los dominicos hasta llegar a la Junta de Fomento de las Californias, quizás el primer intento fuerte de secularización de las misiones californianas. Dicho pro- 
ceso distó bastante de ser armonioso, pues tanto religiosos como civiles se embarcaron en una pugna donde lo que prevaleció, más allá de lo formal, fue el empeño por controlar las mejores tierras y la diezmada mano de obra indígena.

De vuelta a tierras sinaloenses, Rigoberto Rodríguez Benítez, en su trabajo titulado "La legislación Buelnista contra la tenencia comunal de la tierra y sus consecuencias. Sinaloa durante la república restaurada", habla de dos polos de fuerte presencia indígena: uno, el norte de Sinaloa, y el segundo, la región de Ajoya, San Ignacio. Según el autor, las pugnas por el poder impidieron la aplicación de la legislación liberal, que lejos de trastocar los bienes y propiedades religiosas, entre ellos las tierras, transformó de forma contundente las pautas de vida de los indígenas sinaloenses. En la parte de las conclusiones, Rodríguez Benítez comenta sobre los efectos nocivos de la aplicación de la Ley Lerdo en Sinaloa. Tres anexos subsiguientes a las conclusiones buscan mostrar los elementos legales en los cuales se fincó la expropiación de las comunidades indígenas en Sinaloa.

Al cierre de la tercera parte del libro están dos trabajos sobre los indígenas yaquis de Sonora. Primeramente, Raquel Padilla Ramos, con su texto "El trato de la trata. Algunas consideraciones en torno al uso de los conceptos legales para la deportación de los yaquis", invita a reflexionar sobre la importancia del uso de los conceptos en la investigación histórica. Padilla Ramos realiza de forma simultánea un análisis de las acciones para deportar de forma violenta a los yaquis tanto a Yucatán como a Cuba, a finales de siglo XIX y principios del siglo XX, así como los discursos de las autoridades estatales y nacionales involucradas en esas acciones.

El trabajo de Ana Luz Ramírez Zavala, "Los yaquis en el movimiento constitucionalista, 1913-1914", es de alguna manera continuación del texto anterior, dado que el escenario de la lucha revolucionaria en tierras sonorenses mostraba a los indómitos yaquis replegados en la serranía del sur de la entidad, otros fuera de México y no pocos de ellos en el otro extremo del país, empleados en las haciendas yucatecas dedicadas al cultivo y procesamiento del henequén. En palabras de Ramírez Zavala, quien de forma notable presenta un contraste entre diversas versiones acerca de la participación de los yaquis en la revolución mexicana, éstos, como actores sociales, tomaron diferentes decisiones, lo cual se aleja de las visiones clásicas que presentan a este grupo étnico como una colectividad que adopta decisiones homogéneas. La autora muestra su accionar peleando dentro de las filas revolucionarias sonorenses, dentro y fuera de la entidad, pero también cómo, en cierto momento, un número considerable se deslindó de esa alianza tácita para retomar su propia lucha por la 
tierra, donde se puede observar a individuos no yaquis que desempeñaron papeles notables de liderazgo.

Del noroeste mexicano, el texto nos traslada al occidente con dos ensayos que forman la cuarta parte del libro, denominada "Los indios en espacios marginales del Occidente novohispano". María Isabel Marín Tello, en su trabajo "La república de indios de Nuestra Señora de la Asunción Parácuaro, 1787-1810", centra su atención en los litigios de arrendamientos de tierras comunales. En su análisis destaca que los recursos captados en las cajas de comunidad por el trabajo de los indígenas y las rentas de terrenos de comunidad no siempre tuvieron el destino acordado, lo cual enrareció el escenario de Parácuaro. Con el paso de los años, los tres ranchos y dos haciendas de comunidad fueron perdiendo en las subastas públicas que se hacían cada lustro para arrendarlas. De tal forma, los indígenas de Parácuaro buscaron modificar tanto la forma en que se invertían los recursos por arrendamientos como reconsiderar el total de tierras arrendas, pues consideraban que no cubrían las necesidades básicas de los pobladores.

Finalmente, Eduardo González Velázquez, en su trabajo "Lo marginal de la independencia de México. La isla de Mezcala y los indígenas atrincherados", analiza un lustro de resistencia de los habitantes de las inmediaciones de la isla de Mezcala. Durante poco más de cinco años, los aguerridos pobladores de Mezcala, Tlachanilco, El Campo, Chapala, Tizapán, La Palma, San Luisito, Santa Cruz y San Pedro Ixtaticán, armados con lanzas, machetes y hondas, pusieron en jaque a las autoridades reales, las cuales no lograban descifrar la manera de derrotarlos. A decir de González Velázquez, el lustro tratado da cuenta de que, si bien no hubo grandes batallas como las del Bajío, las acciones de los indígenas insurgentes hablan de escenarios diversos en los cuales se desarrolló el movimiento independentista.

Como consideraciones finales, el lector tendrá en sus manos un libro notable en cuanto a la diversidad de enfoques para abordar la temática posmisional, desde una óptica que dista mucho de quedarse en el espacio regional donde se desarrolló; más bien se inserta en discusiones actuales donde el quehacer histórico entabla puentes de diálogo con enfoques interdisciplinarios. Por ello, la historia regional cobra nuevos bríos, apuntando que mejores empresas históricas se están gestando.

Recibido: 09/06/2014. Aceptado: 10/10/2014 